\title{
Modelagem da participação popular em planos de mobilidade urbana
}

\author{
Modeling popular participation in urban mobility plans \\ Modelando la participación popular en planes de movilidad urbana
}

\author{
Adilson Fernandes Indi \\ ORCID: https://orcid.org/0000-0003-0151-8517 \\ Universidade de Brasília, Brasil \\ E-mail: indiadi58@hotmail.com \\ Edwin Francisco Ferreira Silva \\ ORCID: https://orcid.org/0000-0003-1291-3440 \\ Universidade de Brasília, Brasil \\ E-mail: Edw3in@gmail.com \\ Augusto Cesar Brasil \\ ORCID: https://orcid.org/0000-0002-0009-9798 \\ Universidade de Brasília, Brasil \\ E-mail: ambrasil@unb.br
}

\begin{abstract}
Resumo
Este trabalho modelou os elementos que influenciam a efetiva participação popular na elaboração dos planos de mobilidade urbana (PMU). A modelagem dos requisitos se apoiou na metodologia teórica de tipos ideais definidos por Weber, adaptada ao cenário dos municípios brasileiros. O resultado teórico dos requisitos e ferramentas de operacionalização, foram apresentados em mapa mental. A disseminação da informação da participação popular nos PMU foi simulada numericamente considerando a influência de níveis hierárquicos. O modelo numérico foi testado para um estudo de caso de 3 milhões de público-alvo, indicando que $100 \%$ de participação popular seria atingida em 200 meses pelo modelo tradicional, e menos de 50 meses pelo modelo hierárquico. Foram também pesquisadas e apresentadas as principais ferramentas de operacionalização para a efetiva participação popular nos PMU, com base nos trabalhos de (Bickerstaff, Tolley, \& Walker, 2002; Bobbio, 2019; Fung, 2006).
\end{abstract}

Palavras-chave: Participação popular; Plano de mobilidade urbana; Requisitos operacionais da participação popular; Modelo de difusão de Bass; Planejamento.

\begin{abstract}
This work modelled the elements that influence the effective popular participation in the elaboration of urban mobility plans (UMP). The modeling of the requirements was based on the theoretical methodology of ideal types defined by Ewell (1996) and Tomazette (2008), adapted to the scenario of Brazilian municipalities. The theoretical results of the requirements and the operationalization tools were presented in a mental map. The dissemination of information of popular participation in UMP was numerically simulated considering the influence of hierarchical levels. The model was tested for a case study of 3 million target audience, indicating that $100 \%$ of the popular participation would be achieved in 200 months by the traditional model, and less than 50 months by the hierarchical model. Also, the main operationalization tools for effective popular participation were studies and presented, based on the work of (Bickerstaff et al., 2002; Bobbio, 2019; Fung, 2006).
\end{abstract}

Keywords: Popular participation; Urban mobility plan; Implementation tools of popular participation; Bass diffusion model; Planning.

\section{Resumen}

Este trabajo modeló los elementos que inciden en la participación popular efectiva en la elaboración de los planes de movilidad urbana (PMU). El modelado de requisitos se basó en la metodología teórica de tipos ideales definida por Weber, adaptada al escenario de los municipios brasileños. El resultado teórico de los requisitos y herramientas de operacionalización se presentó en un mapa mental. La difusión de información sobre la participación popular en las UGP se simuló numéricamente considerando la influencia de los niveles jerárquicos. El modelo numérico se probó para un estudio de caso de 3 millones de audiencias objetivo, lo que indica que el 100\% de participación popular se lograría en 200 meses con el modelo tradicional y en menos de 50 meses con el modelo jerárquico. También se investigaron y presentaron las principales herramientas de operacionalización para la participación popular efectiva en las UGP, con base en el trabajo de (Bickerstaff et al., 2002; Bobbio, 2019; Fung, 2006).

Palabras clave: Participación popular; Plan de movilidad urbana; Requisitos operativos de participación popular; Modelo de difusión de graves; Planificación. 


\section{Introdução}

A operação do transporte urbano no Brasil é dominada majoritariamente por empresas privadas do setor de transportes urbanos de passageiros. Ao mesmo tempo, a Lei no 12.587, de 3 de janeiro de 2012, que trata de Política Nacional de Mobilidade Urbana (Gomide et al., 2012) estabelece que a participação da sociedade civil deverá ser assegurada na elaboração da política local e no plano de mobilidade. A inclusão da participação popular tem sido uma consequência da evolução da sociedade, tanto no planejamento da mobilidade urbana, quanto em outras políticas setoriais. Sendo assim, a participação popular, tem se tornado indispensável e deixou de ser um assunto apenas filosófico para ser um pré-requisito político-institucional de planejamento e tomada de decisão, tanto no âmbito nacional quanto no cenário internacional (Cascetta \& Pagliara, 2013). Embora o papel de assegurar a participação popular seja de responsabilidade do poder público, o resultado das demandas da participação popular nos transportes, reflete diretamente na gestão das empresas privadas do setor de transportes urbanos de passageiros.

Costa (2016) aponta a Declaração Universal dos Direitos Humanos (DUDH) como um importante instrumento da institucionalização do processo participativo, especificamente em seu artigo 21 que defende a incorporação da sociedade civil na tomada de decisões públicas como forma de garantir o exercício de direito à cidadania e a efetividade das políticas públicas.

Apesar de a participação popular ser um mecanismo já conhecido em algumas políticas setoriais brasileiras desde as décadas de 1970 e 1980, somente na Constituição Federal Brasileira de 1988 que esse processo foi definitivamente incorporado às políticas institucionais. Nessa evolução da participação popular, pode-se perceber a consolidação de alguns mecanismos de operacionalização, tais como, plebiscitos, referendos e audiências públicas, bem como, outros fóruns de caráter variados que ampliaram a efetivação da participação popular em diferentes níveis (Balbim, 2016; Carvalho, 2016).

O Orçamento Participativo (OP) foi uma experiência inovadora de participação popular consolidada no Brasil, originalmente desenvolvida para a cidade de Porto Alegre, e posteriormente disseminada para outros municípios brasileiros (de Sousa Santos, 1998) e mais de 1500 cidades em todo o mundo (Ganuza \& Baiocchi, 2020; Portella et al., 2020). Novas tecnologias de aplicativos e redes sociais têm sido incorporadas à metodologia do OP, consequentemente melhoraram a disseminação da informação e a eficiência da participação popular. Junto com a evolução dos mecanismos de operacionalização de participação popular, alguns trabalhos têm avaliado as metodologias, limitações e impactos sociais da participação social (Cabannes, 2004; Coleman \& Sampaio, 2017; Sewell, Wrderrick Phillips, 1979). Além disso, o termo Participação Popular (PP) varia na literatura, tais como engajamento público (Cascetta \& Pagliara, 2013), ou participação pública (Rowe \& Frewer, 2000; Sewell, Wrderrick Phillips, 1979). O presente trabalho utilizará o termo Participação Popular (PP) ao longo do texto.

No que se refere à política urbana e mobilidade, na Constituição de 1988 não havia citação direta sobre a participação popular. O mecanismo só foi lembrado no Estatuto da Cidade, Lei no 10.257, de 10 de julho de 2001, que regulamentou o capítulo da política urbana previsto nos artigos 182 e 183 da carta magna e na Lei no 12.587, de 3 de janeiro de 2012, que trata de Política Nacional de Mobilidade Urbana (Gomide et al., 2012). As duas legislações estabelecem um conjunto de princípios, diretrizes e normas que norteiam a atuação do poder público e o engajamento popular na produção de políticas, no planejamento da mobilidade e na gestão democrática das cidades. O Estatuto da Cidade e a Política Nacional de Mobilidade Urbana servem de base legal para a concretização da participação popular no planejamento e na gestão das cidades. Contudo, a recente Cartilha de Apoio à Elaboração de Planos de Mobilidade Urbana (M. do D. R. BRASIL, 2019) não menciona a participação popular como um elemento necessário à elaboração de Planos de Mobilidade Urbana (PMU).

A Participação Popular (PP) em geral, não somente para o planejamento da mobilidade urbana, exige uma operacionalização, que é constituída de métodos de participação, instrumentos processuais, mecanismos ou ferramentas para promover o engajamento público. Na prática, a operacionalização não é uma tarefa simples quando se considera o cenário dos municípios brasileiros, seja por causa das limitações institucionais, seja pela falta de conhecimento técnico específico por parte dos envolvidos. A operacionalização da PP na mobilidade urbana pode se dar por meio de audiências/consultas públicas, órgãos 
consultivos, consultas a pequenos grupos, exercícios de projetos colaborativos e outras reuniões participativas com acesso público (Quick et al., 2011).

Alguns autores, como (Bobbio, 2019; Fung, 2006; de Luca, 2014; Quick et al., 2011), apresentaram e analisaram ferramentas que têm sido mais usadas, tanto para a operacionalização quanto para a avaliação da eficiência da PP. (Bobbio, 2019; de Luca, 2014; Wagner, 2013) foram mais específicos em seus trabalhos, na avaliação da PP em projetos de mobilidade.

Observa-se, portanto, que a participação popular deve ser um elemento inseparável das políticas públicas, do planejamento, da implementação e da avaliação de projetos de mobilidade urbana. Adicionalmente, as empresas de transportes urbanos de passageiros são fortemente impactadas pelo resultado do processo de participação popular nos planos de mobilidade urbana. Portanto, a melhor estruturação e operacionalização da participação popular nos PMU podem refletir em menor impacto na gestão das empresas do setor de mobilidade urbana.

Nesse sentido, a participação popular em PMU ainda requer maior evolução para atender todos os setores envolvidos, pois embora os planos de mobilidade urbana dos municípios brasileiros incluam audiências públicas ao longo do processo de implementação, os textos finais têm mais contribuições técnicas do que efetivamente as soluções provenientes da ampla participação pública. (Rowe \& Frewer, 2000) apontaram as limitações das audiências públicas para engajar os cidadãos e disseminar informações, devido à maioria dos participantes em geral não ser especialista ou não possuir conhecimento técnico sobre o tema das audiências.

Para o cenário brasileiro, as audiências e consultas públicas são os principais mecanismos de operacionalização utilizados na participação popular em PMU (Maia, 2015). Tais mecanismos são processos top-down, onde a informação parte de especialistas e dissemina para um público com elevado número de participantes. Por isso, existe atualmente a necessidade de propostas de elementos de operacionalização da PP que resultem em um processo bottom-up, visando tornar a disseminação da informação e as contribuições públicas mais efetivas em PMU.

Para avaliar os elementos que influenciam a efetiva participação popular, o presente trabalho inicialmente aplicou uma metodologia teórica para a busca dos requisitos necessários à participação popular nos processos de elaboração dos Planos de Mobilidade Urbana (PMU) dos municípios brasileiros. Em uma segunda parte, o presente trabalho modelou como a disseminação de informações influencia na eficiência da participação popular. Parte final do trabalho estruturou os requisitos e as principais ferramentas de operacionalização da participação popular nos PMU propondo uma relação causal entre eles.

Para a base teórica da participação popular em PMU, o presente trabalho propôs a estruturação de requisitos necessários à PP por meio do método interpretativo de Max Weber (Elwell, 1996). O estudo também aplicou o modelo burocrático hierárquico de Weber adaptado por Spencer (2014) e modelado matematicamente em Spencer (1998). Após a avaliação dos requisitos e hierarquia, o modelo de Difusão de Bass (Bass, 1969) foi adaptado para simular o impacto da inclusão de níveis hierárquicos na disseminação de informações da participação popular. Os mecanismos de operacionalização da PP foram baseados nos trabalhos de (Bickerstaff et al., 2002; Bobbio, 2019; Fung, 2006; Rowe \& Frewer, 2000)(Rowe \& Frewer, 2000). Além disso, a proposta metodológica publicada em (Leite et al., 2019; de Luca, 2014) foram consideradas como os mecanismos de operacionalização mais adaptáveis à estrutura municipal brasileira.

\section{Metodologia}

Para levantamento dos requisitos de participação popular, na elaboração de PMU, o presente trabalho usou inicialmente o método compreensivo ou interpretativo weberiano (Elwell, 1996). Este método identifica na literatura e nas práticas institucionais, os requisitos e as premissas essenciais que representam a realidade empírica dos desejos da população e, portanto, define quais elementos devem ser contemplados e estruturados na participação popular em PMU. 
Para efeito deste estudo, os tipos ideais definidos por Weber (Tomazette, 2008) representam os requisitos de PP, analisados a partir da realidade social dos municípios brasileiros, as demandas sociais e finalmente a escolha de quais requisitos são contemplados como elementos efetivos de participação popular na elaboração de PMU. Portanto, para efeito da metodologia adotada no presente trabalho, os requisitos (tipos ideais) foram transformados de conceitos abstratos a mapas mentais, permitindo a elaboração de um modelo hierárquico bottom-up, contrapondo ao modelo top-down de participação popular na elaboração dos planos de mobilidade urbana.

A proposta de (Spencer, 2014) de um modelo weberiano adaptado, foi usada no presente trabalho para elaboração do modelo hierárquico bottom-up. Esse modelo considera a hierarquia não somente dos requisitos, para a devida participação popular, mas também a hierarquia geopolítica brasileira da organização de bairros, regiões administrativas, municípios, cidades e estados.

Após o levantamento dos requisitos contemplados na participação popular, utilizando a metodologia weberiana citada acima, eles foram estruturados segundo uma ordem de operacionalização, com o objetivo de definir um "passo-a-passo" para orientar gestores públicos na implementação de PMU com participação popular. Os requisitos fundamentais a serem contemplados em PMU são apresentados abaixo, com descrição e importância de cada um, e posteriormente estruturados.

\subsection{Abrangência espacial - primeiro requisito}

Antes de iniciar a construção do plano de mobilidade urbana é importante considerar as condições locais em que se dá o planejamento, definir abrangência espacial do plano e estruturar estratégias de mobilização dos atores sociais. Naturalmente, o plano de mobilidade urbana abrange toda área do município, o que deve ocasionar a busca pelo envolvimento de todos que residem na pretensa área (Rolnik et al., 2004). No que diz respeito à operacionalização, que será tratada mais adiante, há diversas possibilidades e dinâmicas que podem ser adotadas para facilitar o trabalho de envolvimento da população local na elaboração do plano de mobilidade urbana.

Diante das características diversas de cada município, o ideal é cobrir todos os bairros, ou vilas (caso o município seja muito grande), mesmo que seja apenas com uma parcela representativa, permitindo o envolvimento de todos os atores afetados pelo plano. Outra possibilidade é organizar esse processo conforme as áreas censitárias do (IBGE, 2018). A terceira possibilidade é que esse processo ocorra atendendo as bacias de operações de transporte em cada município. É importante que haja sempre um procedimento criterioso que permita abranger todo território municipal, ficando a critério dos municípios a escolha das estratégias que melhor atendem suas dinâmicas. O trabalho de (Leite et al., 2019) juntamente com (E. Brasil, 2015) é um bom exemplo de PMU com contribuições da participação popular, o qual contemplou adequadamente a abrangência espacial e organização municipal.

\subsection{Aspectos técnicos e institucionais - segundo requisito}

Entende-se que a definição da estrutura técnico-administrativa e institucional deve ser uma das primeiras medidas do prefeito e seus colaboradores políticos (gestores ligados a órgãos participantes do planejamento). É uma das etapas mais importantes em todo processo participativo. É a equipe técnica criada pelo prefeito que vai conduzir todo processo participativo, por isso, ela deve ser altamente qualificada e com habilidades de mediação para que o processo participativo tenha efetividade e atinja o público. Os trabalhos de Cascetta e Pagliara (2013) e Fung, (2006) mostram que o arranjo institucional e governança do processo, são elementos determinantes para um efetivo processo de participação popular.

Considerando como sendo um requisito, mas também faz parte da operacionalização, montar uma equipe interdisciplinar é fundamental. Tal equipe precisa ter capacidade de mobilização de atores, experiência de gestão política, capacidade técnica e experiência no processo de construção social do consenso. Os membros da equipe técnica designados devem 
possuir habilidade de mediação e terem credibilidade junto à população. Esses membros também devem adotar uma postura de neutralidade e idoneidade, possuir facilidade de comunicação, não podem ser políticos ou pessoas demasiadamente identificadas com correntes ideológicas (E. Brasil, 2015).

A equipe precisa ser definida com atribuições de competências claras e objetivas, e esta por sua vez, deve estabelecer prazos e cronogramas, com datas de cada atividade a ser executada. A mobilização deve ir além da equipe que irá comandar os trabalhos, é preciso o engajamento do prefeito, dos secretários ligados à área e dos órgãos institucionais que participam da elaboração do plano. É igualmente importante a mobilização política dos vereadores que irão participar na deliberação final do plano, transformando-o em lei municipal. A participação das estruturas superiores da executiva não pode favorecer a interferência das decisões políticas verticais ou com motivações econômicas sobre o trabalho técnico. Deve haver certa autonomia para que a equipe técnica, em constante contato com os segmentos envolvidos, viabilize as demandas populares e tenha a legitimidade democrática do plano (E. Brasil, 2015). Um exemplo de estrutura hierárquica de gestão do plano de mobilidade urbana foi proposto por (E. Brasil, 2015).

Em alguns casos em que os municípios possuem déficit de quadros técnicos qualificados para gerenciar a construção do plano de mobilidade, é possível que se recorra aos serviços terceirizados de consultoria. Mas, mesmo quando a construção do plano é dirigida pelos consultores, o município deve criar equipe que irá acompanhar e fiscalizar a implementação do processo participativo. Todas as diretrizes que orientam a participação popular devem ser discutidas com os consultores e aplicadas durante o planejamento. Geralmente os consultores possuem conhecimentos apurados nas áreas em que atuam, porém, isso não deve condicionar o afrouxamento de controle por parte da equipe responsável pelo acompanhamento do processo (Wahl, 2013).

\subsection{Mapeamento e envolvimento de atores sociais - terceiro requisito}

Adotando a definição do trabalho de (E. Brasil, 2015), atores sociais são indivíduos ou personalidades; organizações sociais (organizações comunitárias, associações de moradores, associações comerciais, ONGs, etc.); sindicatos; movimentos sociais; instituições técnicas; organizações religiosas; operadores do sistema de mobilidade urbana; as entidades financiadoras; agências governamentais; entidades de classes; entre outros. Ou seja, atores sociais são todos aqueles que podem afetar e serem afetados positiva ou negativamente pelo planejamento de mobilidade urbana, que de alguma forma, seu envolvimento exerce influência direta ou indireta nos objetivos e resultados.

Fung, (2006) descreveu a importância dos atores sociais envolvidos no processo de PP, e o trabalho de Cascetta e Pagliara (2013) aprofundou a tipologia dos atores envolvidos, definindo maior ou menor força de participação.

Os gestores públicos ou equipe técnica responsável pela elaboração do plano precisam fazer um levantamento detalhado das organizações existentes e das personalidades relevantes no município, com o propósito de viabilizar a participação de todos no planejamento. Vale ressaltar que em alguns casos existirão organizações bem atuantes, mas que não possuem estatuto e/ou registro formal. Essas organizações sociais devem ser incluídas no inventário de atores mapeados.

Ao realizar o inventário de atores, a equipe técnica deve segmentá-los segundo interesses específicos de cada grupo. Nesse caso, deve ser elaborado o perfil de cada grupo ou personalidade, definir claramente que interesses representa. É uma forma de facilitar a mediação de conflito de interesses nos momentos de debates e deliberação, possibilitando assim um equilíbrio de forças e uma participação mais equitativa. Também seria uma forma de evitar que grupos de maiores interesse exerçam grandes influências na tomada de decisões e se sobreponham ao desejo da maioria, visto que, o mediador (equipe gestora) deve regular as relações de poder e garantir equidade (E. Brasil, 2015).

Segundo Ibeas et al. (2011), para envolvimento de atores na construção do plano é preciso ter objetivos claros sobre como deve ser conduzido o processo participativo. Acrescentam ainda, que no início da construção de plano, deve ser proporcionado o envolvimento maior da população a partir de grupo focal mais amplo. A finalidade da formação de um grupo focal mais amplo 
no início do planejamento é conhecer as experiências, as percepções e opiniões referentes aos problemas de mobilidade urbana no município ou em cada localidade onde se realiza o processo participativo. Como operacionalização, para envolver a população no planejamento, o grupo gestor deve realizar o mapeamento de atores relevantes em cada localidade, enviar carta convite formal para esses atores. É importante estabelecer o número de representantes que cada organização deve indicar para participar do processo. Em geral, as organizações indicam dois representantes (Ibeas et al., 2011).

\subsection{Empoderamento de atores - quarto requisito}

$\mathrm{O}$ termo empoderamento, originalmente denominado de "empowerment" em inglês, implica, segundo (Kleba \& Wendausen, 2009), processos de mobilizações e práticas que visam promover e impulsionar grupos e comunidades para obtenção de melhores condições de vida e obtenção de maior autonomia política, sociocultural, econômica e ambiental. O requisito de empoderamento é fundamental para dar voz, visibilidade, influência, capacidade de ação e decisão aos indivíduos, com o propósito de buscar equilíbrio nas relações de negociação em Participação Popular (Baquero, 2012). A reflexividade, autoconfiança, conhecimento e responsabilidade precisam ser elementos inerentes desse processo de Participação Popular.

Segundo destacam Kleba e Wendausen (2009), o empoderamento nos espaços de participação popular pode ocorrer em três dimensões, quais sejam: pessoal ou psicológico, grupal ou organizacional e estrutural ou político. No caso específico deste trabalho, a relevância que se dá ao empoderamento é para a dimensão estrutural ou político, porque é nela que ocorrem os processos políticos da conformação da vida social e da redistribuição do poder decisório.

Outro aspecto importante do empoderamento foi abordado por Bobbio (2019), que observou que o empoderamento se dá aos cidadãos, mas também ao político gestor, ou seja, quanto maior a participação popular, maior o empoderamento do político para a tomada de decisão. O poder público local deve promover estruturas favoráveis e desenvolver estratégias de envolvimento, incluindo a disseminação da informação em cada etapa do plano de mobilidade, convocação ao debate, exposição do orçamento, recursos aplicados e quais benefícios do plano.

\section{5 "Accountability" - transparência - quinto requisito}

"Accountability", termo que corresponde em português à transparência institucional, é a base norteadora de todo processo participativo. Ela deve estar presente do início ao fim do processo de planejamento. A transparência é aspecto que visa criar a relação de confiança entre o poder público e a população, inclusive, entre diferentes segmentos da sociedade envolvidos no planejamento da mobilidade. A transparência ocorre na medida em que as informações intrínsecas ao processo são amplamente compartilhadas, detalhando a real situação do planejamento para os envolvidos. Também é importante ressaltar que o feedback é um elemento importante da transparência (Bickerstaff et al., 2002; Wahl, 2013).

A transparência requer um trabalho cuidadoso da equipe gestora que conduz os trabalhos do plano. As informações devem ser tratadas e divulgadas de forma a atingir todos os segmentos a serem afetos pelo plano. É necessária a máxima divulgação do processo de construção do plano de mobilidade urbana e as atividades que o envolve. A divulgação deve ser realizada em diversos meios de comunicação, quais sejam: websites da administração pública e outros criados especificamente para essa finalidade, redes sociais, rádios comunitárias, emissoras de televisões locais, jornais e outros veículos da imprensa. Podem ser utilizadas propagandas, informativos, campanhas, anúncios, slogan, entre outros meios de informação. A comunicação nesse caso, deve ser uma prática transversal e permanente durante todo trabalho que envolve o PMU desde a fase de preparação até a implementação e revisão (E. Brasil, 2015)

Segundo (E. Brasil, 2015), é preciso que todas as informações referentes ao processo de construção do plano sejam divulgadas amplamente, com coerência, clareza e linguagem acessível a todos os interessados. Assim como devem ser divulgados periodicamente todos os resultados obtidos em cada etapa do processo de planejamento. Esses resultados devem estar acessíveis 
em diversos canais de comunicação do plano e repassado diretamente nas reuniões e debates públicos. Devem ser criadas e mantidas alguns canais de comunicação contínuos (internet, telefone e redes sociais) para realizar campanhas educativas, promover ou ensinar sobre vários temas em debate.

A difusão da informação não pode ser apenas uma mera formalidade, mas um elemento fundamental de fortalecimento do vínculo entre a equipe técnica que coordena as atividades e a população, através de uma relação de confiança estabelecida entre as partes. Um dos aspectos mais relevantes desse vínculo de confiança é o feedback. A equipe deve sempre dar retorno à população, mostrando para este que suas contribuições estão sendo considerados no plano, bem como apresentar resultados parciais de cada etapa do trabalho (Wahl, 2013). O retorno é fundamental para manter estímulo à participação, como para reafirmar o compromisso de um trabalho transparente (E. Brasil, 2015).

A transparência pressupõe o estabelecimento de regras claras pela equipe gestora no processo de construção do PMU. As informações devem conter linguagem acessível e transparente, democratizando assim o seu acesso para todos os envolvidos (Rolnik et al., 2004).

\subsection{Diversidade e interação colaborativa - sexto requisito}

A valorização da diversidade e a inclusão social são dimensões importantes que também devem ser levadas em consideração no processo de participação popular no planejamento da mobilidade urbana. A diversidade e inclusão permitem o estabelecimento de um processo interativo solidário, colaborativo, cooperativo e equitativo. Quando observadas essas dimensões, principalmente, quando incluídos segmentos mais vulneráveis, os resultados do PMU tendem a traduzir interesses coletivos (Bickerstaff et al., 2002).

\subsection{Modelo o numérico da participação popular}

Os requisitos apresentados nos itens anteriores deem ser contemplados na participação popular durante elaboração de PMU, podendo fazer parte de um "checklist" aos gestores públicos. A modelagem apresentada neste item não é diretamente aplicável por parte de gestores, mas faz parte do estudo do presente trabalho que analisa a influência de estruturas hierárquicas sociais na participação popular. Tal modelo visa indicar como os níveis hierárquicos aumentam a eficiência da disseminação da informação na participação popular.

Em geral, a estrutura orgânica hierárquica que se encontra no Brasil é de bairro, vila, cidade, região metropolitana, município e estado. Para efeito dos PMU a dimensão dos Estados brasileiros extrapola o conceito de região urbana.

O trabalho de (Spencer, 2014) apresentou um modelo da evolução burocrática e crescimento do estado a partir da teoria de Marx Weber, com a hierarquização e descentralização política sendo os elementos que podem limitar ou promover o desenvolvimento do Estado. O fluxo de recursos, ou bens econômicos que definem o crescimento do estado, já tinham sido modelados matematicamente em (Spencer, 1998) usando equações adaptadas de Lotka-Volterra para predador-presa. Já o modelo de difusão de Bass, (1969) adaptado para diversas aplicações, tem semelhanças ao modelo predador-presa, e pode ser visto como uma evolução do equacionamento de fluxo de bens ou informação. O presente trabalho propõe um modelo adaptado de difusão de Bass para avaliar a influência dos níveis hierárquicos e de propagadores da informação que promovem maior, ou menor, disseminação do conhecimento na participação popular em PMU. Partindo dessa formulação, o modelo de disseminação da informação na participação popular, pode ser descrito segundo a Eq. 1.

$$
\frac{d N(t)}{d t}=p[m-N(t)]+\frac{q}{m} N(t)[m-N(t)]
$$


Onde $N(t)$ é o número de participantes efetivos no tempo $t, m$ é a população total ou potenciais participantes, $p$ é o coeficiente de disseminação pela inovação (que se refere àqueles participantes que aderem ao processo pela atração ao novo) e $q$ é o coeficiente de disseminação pela imitação (que se refere àqueles participantes que aderem ao processo pela aceitação do outro, no boca-a-boca). Essa equação pode ser representada em diagrama de fluxo e disseminação não-hierárquica mostrado da Figura. 1.

Figura 1 - Modelo de fluxo e hierarquia da disseminação da informação na participação popular em PMU.
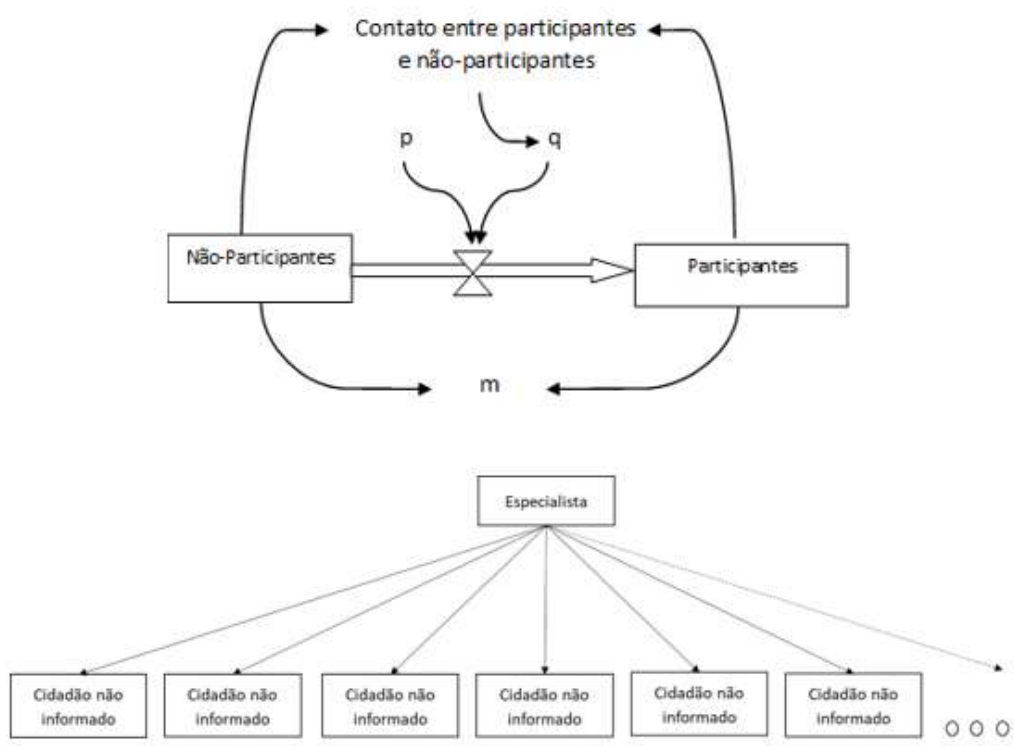

Fonte: Autores

O modelo descrito acima representa uma forma de participação popular em PMU, onde a disseminação da informação parte dos gestores e especialistas, diretamente para o nível do cidadão, geralmente em audiências públicas. O presente trabalho analisa a influência da inclusão de novos níveis hierárquicos para participação popular em PMU. Ou seja, em primeiro nível, a propagação da informação se daria em reuniões com menor número de pessoas, entre especialistas e grupos mais informados sobre o tema mobilidade. Tais reuniões poderiam ser realizadas em ambientes institucionais, com recursos audiovisuais $\mathrm{e}$ informações de maior elaboração técnica. Depois a disseminação continuaria a ser propagada para outros níveis hierárquicos, onde os grupos mais informados teriam contato com grupos menos informados, sucessivamente, em ambientes cada vez mais próximos do cidadão, tais como as representações de bairros. Para simular o impacto da inclusão de novos níveis hierárquicos na disseminação da informação em processo de participação popular em PMU, o presente trabalho propôs o modelo de fluxo e representação hierárquica, como pode ser visto na Figura 2. Tal modelo equivale a repetir a mesma equação de fluxo em um segundo nível hierárquico, onde o resultado de um sistema alimenta o segundo sistema idêntico. 
Figura 2 - Modelo de fluxo da participação popular com inclusão de níveis hierárquicos.
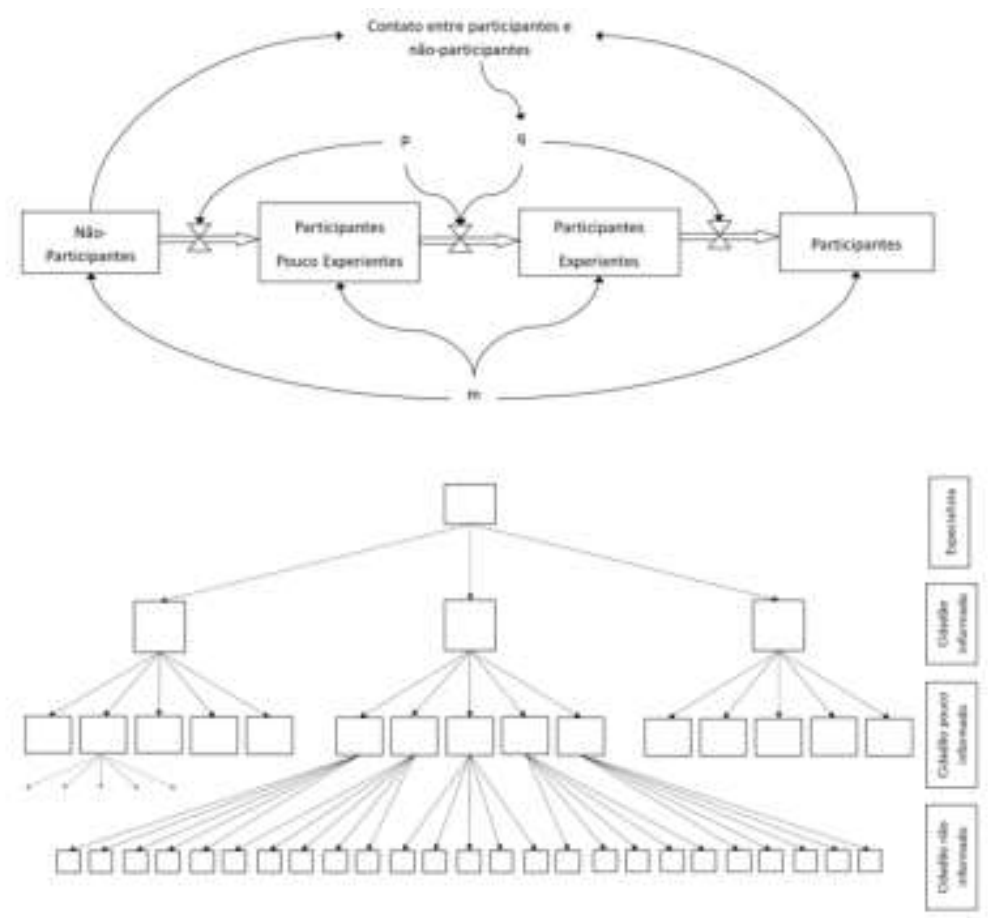

Fonte: Autores

Em um sistema com mais níveis hierárquicos, com na Figura 2, a capilarização da informação permite atingir um número muito maior de pessoas. Por exemplo, para uma relação de 1/10 na disseminação de informação, ou seja, cada pessoa entra em contato com outras 10 pessoas, a Fig. 1 mostra que a informação de um especialista atingiria diretamente 10 pessoas, enquanto no modelo da Fig. 2, a informação de um especialista atingiria 1000 pessoas na base hierárquica.

Para a simulação numérica da difusão da informação neste trabalho, algumas premissas e condições precisaram ser assumidas para garantir a possibilidade de comparação entre os modelos hierárquicos (Figura 1 e Figura 2). Uma premissa assumida foi manter os coeficientes de inovação e imitação igual para os dois modelos ( $p$ e $q$ ), pois assim foi possível avaliar a influência apenas da inclusão dos níveis hierárquicos. O valor de $p$ foi fixado em 0,05 seguindo sugestões dos trabalhos de Ganjeizadeh et al., (2017); Lilien et al., (2000); Ratcliff e Doshi (2016). O valor de $q$ foi determinado como uma proporção do contato entre participantes e não-participantes. A condição da relação da disseminação de informação foi simulada com valores constantes iguais para os dois modelos hierárquicos, mas foram realizadas três simulações numéricas do modelo com relações de 1/10,1/3 e 1/2, significando que cada pessoa informada entra em contato com outras 10,3 ou 2 pessoas, respectivamente, igual para os dois modelos.

\subsection{Operacionalização - ferramentas}

Como descreve Bobbio, (2019) e as referências citadas pelo autor, existem muitos arranjos, metodologias e técnicas para envolvimento da participação popular. A participação popular evoluiu a partir de modelos unidimensionais para modelos hierárquicos e tridimensionais. Um dos primeiros modelos unidimensionais foi proposto por Arnstein, (1969), e um modelo cúbico tridimensional foi proposto por (Fung, 2006). O presente trabalho propõe uma abordagem hierárquica como ferramenta de operacionalização da participação popular em PMU, e segue as sugestões de Bobbio (2019); Fung (2006) e Rowe e Frewer (2000) no sentido de que a metodologia mais eficiente de participação popular será aquela que mais se adequar à sociedade em questão e ao cenário atual. No Brasil, há a possibilidade de aplicação de técnicas mais disruptivas que as tradicionalmente usadas, contudo, sempre considerando fortemente as características da sociedade brasileira e a sua organização hierárquica geopolítica. 
Em termos gerais, há um entendimento na literatura de que o envolvimento da população é mais útil em um estágio inicial do processo, quando os objetivos e questões gerais do plano são definidos (Wahl, 2013), já que em níveis mais avançados, o planejamento se torna mais complexo e técnico, e dessa forma, dificulta a influência e participação de atores com menos conhecimento técnico. Tal entendimento reforça a necessidade da proposta do modelo da Figura 2. Portanto, no que se refere à operacionalização da participação popular, é preciso que os especialistas e gestores programem atividades convidativas, em locais de fácil acesso e nos horários que proporcionam maior participação da população (Leite et al., 2019). Os calendários e pautas devem ser divulgados previamente e a dinâmica das discussões deve levar em consideração a diversidade dos grupos representados nos debates, facilitando o maior engajamento popular, sentimento de pertencimento e equidade decisória, evitando grupos dominantes (E. Brasil, 2015).

Quanto aos métodos de operacionalização, a E. Brasil (2015) destaca a importância de mesas de discussão, grupos de trabalho, oficinas interativas etc. Ressalta também que os espaços de debate e tomadas de decisão devem ter uma boa representação democrática, plural, e que minimizem as possibilidades de conflitos que inviabilizem o consenso. Em relação à temporalidade, é importante a realização de fóruns temporários, como audiências e consultas públicas, mas é igualmente importante a constituição de espaços transversais e permanentes de participação popular.

Ibeas et al. (2011) destacam a importância de realizar oficinas e outros métodos dinâmicos na busca de soluções para o PMU. Ressaltam que nesses espaços os atores podem ser divididos em grupos compatíveis com os eixos temáticos do plano. Inicialmente devem ser expostos todos os problemas que afetam a mobilidade e, a partir daí, por meio de oficinas interativas, empreenderem as discussões sobre os problemas apresentados. Cada grupo deve ficar responsável para analisar, debater e apresentar soluções para seu eixo temático junto a outros participantes. Após apresentação, o problema é debatido por coletivo dos participantes, o qual, naturalmente incorpora as opiniões coletivas, decididas democraticamente, observando as orientações técnicas necessárias.

É importante que todas as discussões e debates sejam registrados. O sucesso de oficinas depende da capacidade de condução das atividades por parte dos moderadores, daí a importância dos registros para verificar que procedimentos devem ser revisados em outros encontros.

Assim, a construção do PMU deve contemplar um processo participativo dinâmico, e com a utilização variada de métodos interativos e inovadores. Bickerstaff et al. (2002) e Cascetta e Pagliara (2013) avaliaram métodos de operacionalização de processos participativos, os quais devem estar presentes na elaboração de PMU.

Os métodos inovadores devem ser mesclados com os tradicionais, ampliando as possibilidades de os participantes terem mais espaços de debates e interação. Os métodos tradicionais representam consultas e audiências públicas, reuniões públicas, exposições públicas, entre outros (Bickerstaff et al., 2002).

Métodos mais recentes de planejamento e avaliação de participação popular, utilizam ferramentas matemáticas, de Luca (2014), que aplicaram uma análise multicritério e método hierárquico, para determinar os critérios de maior influência na participação popular, durante a proposta e implementação do Plano de Mobilidade da região da Campania, Sul da Itália. Em de Luca (2014) foi feita uma pesquisa de opinião da população quanto aos critérios que influenciavam as opções sugeridas no PMU, e em seguida foi aplicada a ferramenta multicritério para implementação das opções. O presente trabalho não pretendeu aplicar uma ferramenta de operacionalização com estudo de caso de PMU, nem mesmo, realizar uma avaliação matemática semelhante à de Luca, (2014), já que para tal seria necessário estruturar a metodologia de elaboração do PMU em todos os momentos da elaboração de um PMU.

Contudo, a metodologia de operacionalização apresentada em de Luca (2014) mesmo não sendo testada no contexto brasileiro, é a ferramenta que mais se adequa à proposta de níveis hierárquicos do presente trabalho. Por outro lado, a metodologia 
de operacionalização de Leite et al. (2019) foi testada no contexto brasileiro, com analogias àquela apresentada em de Luca (2014), e possui uma hierarquização a qual é objeto da proposta deste trabalho.

\section{Resultados e Discussão}

O resultado da primeira parte do presente trabalho, foi a aplicação metodológica para a pesquisa e levantamento dos requisitos necessários à participação popular em PMU. A construção de requisitos ideais da participação popular, com base método interpretativo de Max Weber (Elwell, 1996), foi apresentada nos itens 2.1 ao 2.6 do presente trabalho. Tais requisitos são fundamentais para orientar a operacionalização da participação popular no processo de elaboração de PMU. Os requisitos apresentados neste trabalho são contribuições para os gestores públicos interessados em seguir um checklist dos elementos de implementação da participação popular, tornando esse processo mais efetivo. Já no item 2.8, foram apresentadas as ferramentas de operacionalização da participação popular em PMU. Portanto, unindo os requisitos apresentados nos itens 2.1 a 2.6, com as ferramentas de operacionalização do item 2.8, obteve-se uma estrutura de mapa mental para elaboração de PMU, com plena participação popular, apresentado na Fig. 3. O mapa mental fornece uma visão integrada de como os requisitos de operacionalização da participação popular estão conectados aos requisitos básicos que necessariamente devem ser contemplados no processo de participação popular.

Figura 3 - Mapa mental da aplicação dos requisitos e ferramentas operacionais, para a efetiva Participação Popular na elaboração de PMU.

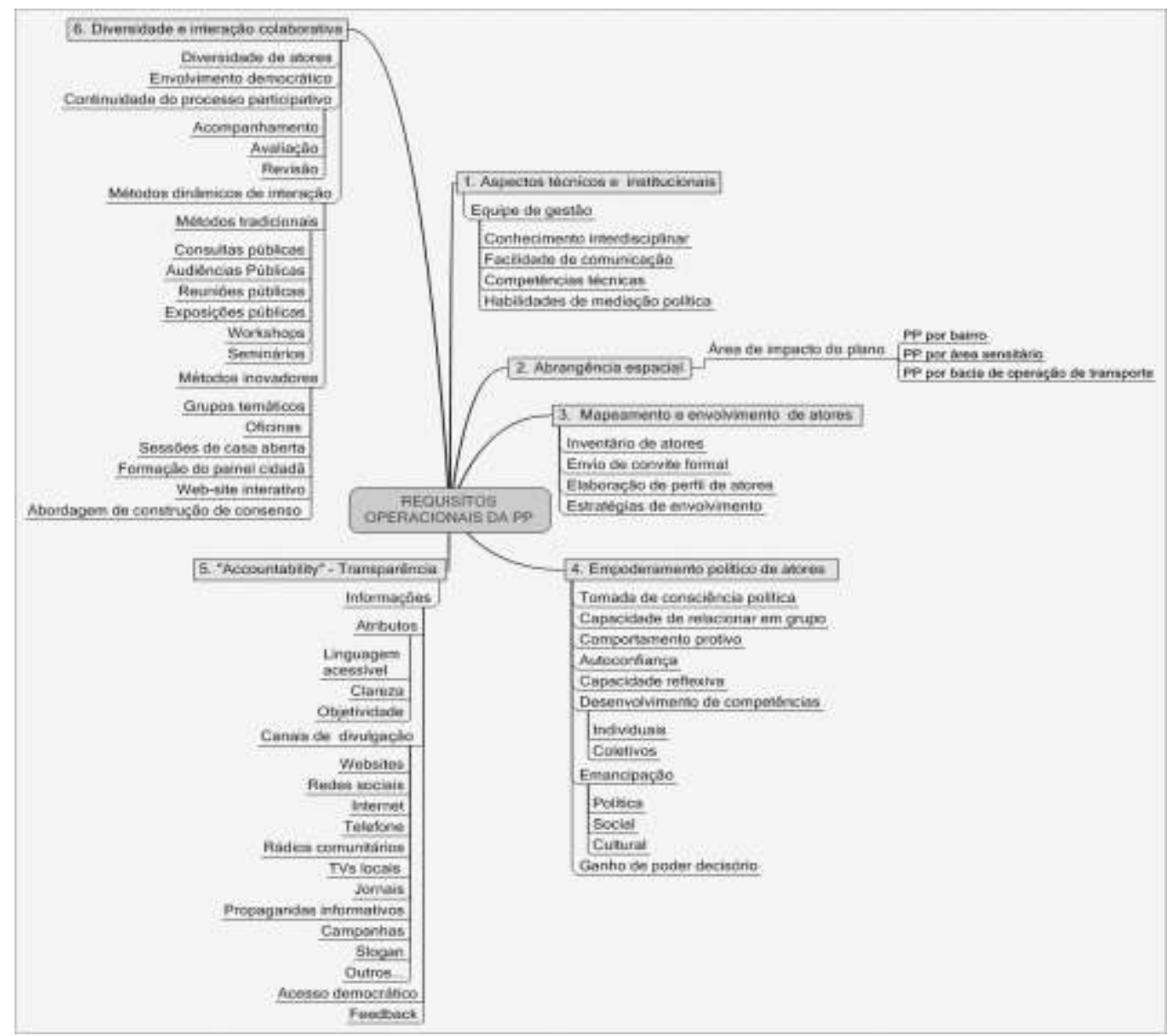

Fonte: Autores 
No item 2.7 foi apresentado um modelo modificado de difusão de Bass (1969) para a disseminação da informação. Tal modelo serviu para avaliar a influência da inclusão de níveis hierárquicos no número de participantes em um processo de elaboração de PMU. Para o modelo hierárquico, o aumento da eficiência da participação popular na elaboração de PMU foi avaliado para um caso de uma população alvo de 3 milhões de habitantes. A eficiência da participação popular foi medida pelo número de pessoas informadas (participantes) ao longo do tempo, ou seja, quanto mais rápido a informação for disseminada, mais eficiente será o processo de participação. Variou-se a relação de quantas pessoas mais informadas entram em contato com pessoas menos informadas. O modelo foi implementado numericamente com simulações do modelo tradicional (Figura 1) comparado ao modelo hierárquico (Figura 2) com relações de disseminação da informação de 1/2,1/3 e 1/10. Na Figura 4, tais relações são apresentadas identificadas como $2 x, 3 x$ e 10x, onde $2 x$ significa que uma pessoa informada dissemina informação para outras 2 pessoas, $3 x$ significa que uma pessoa dissemina para outras 3 , e 10x significa que uma pessoa dissemina para outras 10.

Figura 4 - Resultado da simulação numérica de níveis hierárquicos na disseminação da informação e efetiva participação popular na elaboração de PMU.

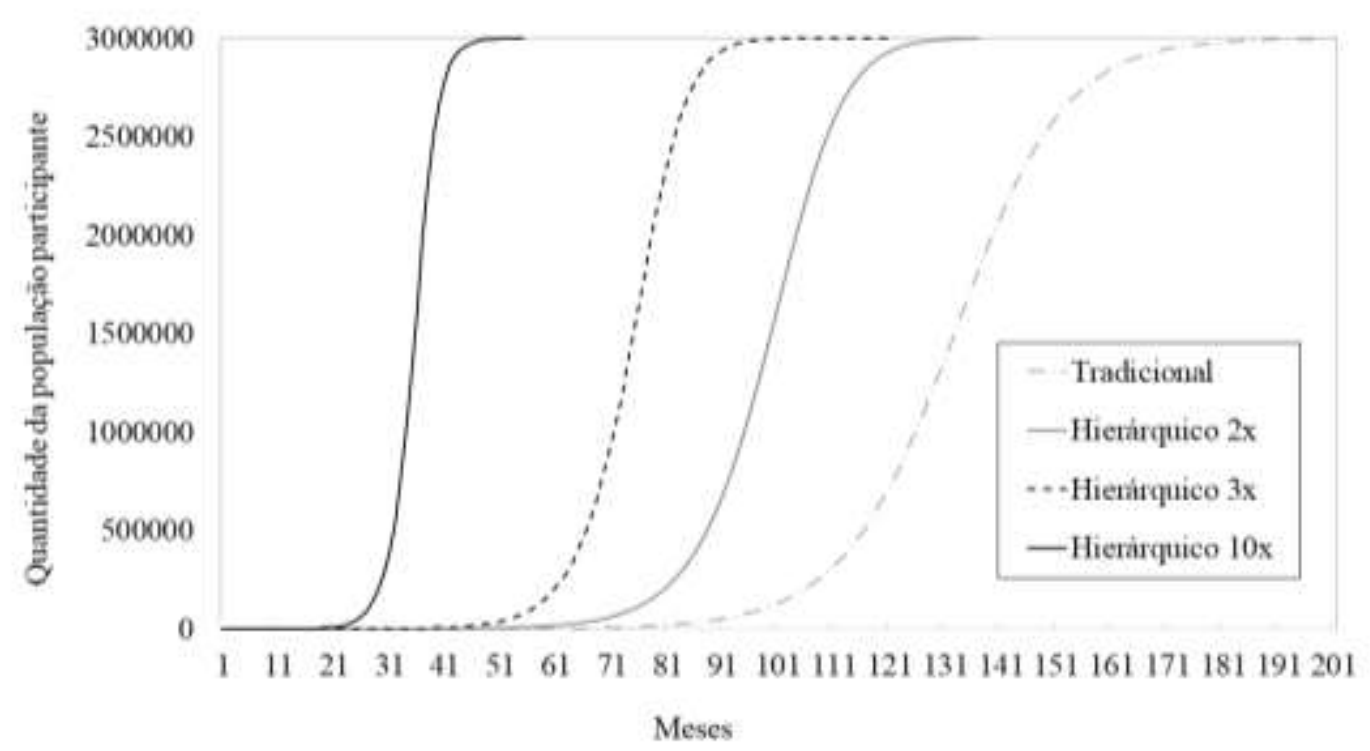

Fonte: Autores

Como resultado da simulação, apresentado na Figura 4, observa-se que o modelo tradicional (não hierárquico), linha quebrada cinza, consegue disseminar a informação para 100\% da população ao final de 200 meses. O modelo hierárquico, linha preta sólida, para a mesma relação de $10 x$ da disseminação do modelo tradicional, dissemina a informação para $100 \%$ da população em menos de 50 meses. Mesmo quando o modelo hierárquico foi simulado com relações de $3 x$ (linha preta quebrada), e relação de $2 x$ (linha cinza sólida), a informação foi disseminada para 100\% da população em 90 e 120 meses respectivamente. Os resultados da simulação numérica mostram a importância da inclusão de níveis hierárquicos na disseminação da informação e efetiva participação popular.

Como resultado da análise de ferramentas operacionalização, com base nas referências analisadas no item 2.8, o presente trabalho propõe que as ferramentas dispostas na Tabela 1 sejam os elementos mínimos contemplados na operacionalização de participação popular em PMU. 
Tabela 1 - Ferramentas de operacionalização de participação popular em Plano de Mobilidade Urbana.

\begin{tabular}{|c|c|}
\hline MÉTODOLOGIA & OPERACIONALIZAÇÃo \\
\hline MATERIAL IMPRESSO & Cartas, flyers, posters, relatórios \\
\hline CONTATO DE MÍDIA & Celular, TV e rádio \\
\hline INTERNET & Postagens em redes sociais e sites \\
\hline PESQUISAS & Questionários e pesquisas de opinião \\
\hline EVENTOS & Palestras, reuniões e encontros \\
\hline ENGAJAMENTO DE ATORES & Painel cidadão, grupos focais, mesas de negociação técnica \\
\hline ENGAJAMENTO ABRANGENTE & Seminários, congressos, júri popular e referendum. \\
\hline
\end{tabular}

Fonte: Autores

\section{Considerações Finais}

O presente trabalho modelou os elementos que influenciam a efetiva e eficiente participação popular na elaboração de planos de mobilidade urbana (PMU). Inicialmente, o trabalho se apoiou em metodologia teórica de Weber para o levantamento dos requisitos necessários à participação popular nos processos de elaboração dos planos de mobilidade urbana (PMU), visando aplicação no cenário dos municípios brasileiros. A modelagem teórica dos requisitos e as ferramentas de operacionalização, foram apresentados em forma de mapa mental.

Visando propor uma estrutura de maior participação popular nos PMU, o presente trabalho utilizou um modelo modificado de difusão de Bass (1969) hierárquico, com simulação numérica da disseminação da informação, e avaliação da influência dos níveis hierárquicos na maior disseminação da informação da participação popular. O modelo proposto foi simulado para uma população de 3 milhões de público-alvo, indicando que no modelo tradicional a informação atingiria $100 \%$ da população em 200 meses, enquanto no modelo hierárquico mais eficiente, a informação atingiria $100 \%$ de participação da população em menos de 50 meses. Como fechamento do estudo, foram levantadas e apresentadas as principais ferramentas de operacionalização para a efetiva participação popular nos PMU. Tais ferramentas se basearam nos trabalhos de Bickerstaff et al. (2002); Bobbio (2019); E. Brasil (2015); Fung (2006). Adicionalmente, foram analisadas as propostas metodológicas publicadas em de Luca (2014) e Leite et al. (2019), sendo as ferramentas de operacionalização mais adequadas ao modelo hierárquico do presente trabalho.

Ficou patente ao longo do artigo que a participação popular é um processo complexo, que requer recursos teóricos metodológicos para sua concepção e operacionalização. O presente trabalho ao buscar a modelagem teórica e numérica para subsidiar a Participação Popular (PP) na elaboração dos PMU, evidencia a necessidade de idealização da PP, com os devidos conceitos, planejamento, organização, capacidade institucional e capital humano para sua e efetivação. Esse processo só poderá ser alcançado de fato, e ser duradouro, quando o envolvimento de atores observar os passos e elementos apontados no presente trabalho.

Portanto, para trabalhos futuros, estudos aplicados deverão ser realizados no sentido de verificar a eficácia, tanto do modelo hierárquico proposto, quanto das ferramentas de operacionalização de participação popular em PMU. Para a medição de eficácia, deverão ser consolidados indicadores que fornecerão a performance da disseminação da informação segundo o modelo hierárquico, bem como, indicadores de performance das ferramentas de operacionalização usadas. Para a aplicação experimental do presente estudo, inicialmente, sugere-se um estudo piloto, sem efetivamente aplicar as propostas do presente trabalho em ações de um PMU. Com a realização e resultados do estudo piloto, serão feitas a calibração e a adaptação do modelo hierárquico e das ferramentas de operacionalização aos cenários locais específicos. E finalmente, após adaptação, indica-se o método proposto no presente trabalho para uso em PMU. 


\section{Referências}

Arnstein, S. R. (1969). A Ladder Of Citizen Participation. Journal of the American Institute of Planners, 35(4), 216-224. Routledge. https://doi.org/10.1080/01944366908977225

Balbim, R. N. O. (2016). Geopolítica das cidades: velhos desafios, novos problemas. Instituto de Pesquisa Econômica Aplicada - ipea. https://www.ipea.gov.br/portal/images/stories/PDFs/livros/livros/161005_a_geopolitica.PDF

Baquero, R. V. A. (2012). Empoderamento: instrumento de emancipação social?-uma discussão conceitual. Revista debates, 6(1), 173.

Bass, F. M. (1969). A New Product Growth for Model Consumer Durables. Management Science, 15(5), 215-227-215-227. http://www.jstor.org/stable/2628128

Bickerstaff, K., Tolley, R., \& Walker, G. (2002). Transport planning and participation: the rhetoric and realities of public involvement. Journal of Transport Geography, 10(1), 61-73. https://www.sciencedirect.com/science/article/pii/S0966692301000278

Bobbio, L. (2019). Designing effective public participation. Policy and Society, 38(1), 41-57. https://doi.org/10.1080/14494035.2018.1511193

BRASIL, E. (2015). Sete Passos: Como construir um plano de mobilidade urbana.

BRASIL, M. do D. R. (2019). Cartilha de apoio à elaboração de planos de mobilidade urbana para municípios com até 100 mil habitantes. https://www.mdr.gov.br/images/stories/ArquivosSEMOB/cartilha-apoio_a_elaboracao-planos_de_mobilidade-100milhab.pdf

Cabannes, Y. (2004). Participatory budgeting: a significant contribution to participatory democracy. Environment and Urbanization, 16(1), 27-46. https://doi.org/10.1177/095624780401600104

Carvalho, C. H. R. de. (2016). Mobilidade Urbana: avanços, desafios e perspectivas. IPEA.

Cascetta, E., \& Pagliara, F. (2013). Public Engagement for Planning and Designing Transportation Systems. Procedia - Social and Behavioral Sciences, 87, 103-116. Elsevier B.V. http://dx.doi.org/10.1016/j.sbspro.2013.10.597

Coleman, S., \& Sampaio, R. C. (2017). Sustaining a democratic innovation: a study of three e-participatory budgets in Belo Horizonte. Information, Communication \& Society, 20(5), 754-769. https://doi.org/10.1080/1369118X.2016.1203971

Costa, M. A. O. (2016). O Estatuto da Cidade e a Habitat III: um balanço de quinze anos da política urbana no Brasil e a nova agenda urbana. IPEA.

Elwell F. (1996). The Sociology of Max Weber. http://www.faculty.rsu.edu/ felwell/Theorists/Weber/Whome.htm.

Fung, A. (2006). Varieties of participation in complex governance. Public administration review, 66, 66-75.

Ganjeizadeh, F., Lei, H., Goraya, P., \& Olivar, E. (2017). Applying Looks-like Analysis and Bass Diffusion Model Techniques to Forecast a Neurostimulator Device with No Historical Data. Procedia Manufacturing, 11, 1916-1924. https://www.sciencedirect.com/science/article/pii/S2351978917305425

Ganuza, E., \& Baiocchi, G. (2020). The power of ambiguity: How participatory budgeting travels the globe. Journal of Deliberative Democracy, 8(2).

Gomide, A. de Á., Carvalho, C. H. R. de, Pereira, R. H. M., Lima Neto, V. C., \& Galindo, E. P. (2012). A nova lei de diretrizes da Política Nacional de Mobilidade Urbana. IPEA, 27, 27-39.

Ibeas, A., dell'Olio, L., \& Montequín, R. B. (2011). Citizen involvement in promoting sustainable mobility. Journal of Transport Geography, 19(4), 475-487. https://www.sciencedirect.com/science/article/pii/S0966692310000074

IBGE. (2018). Dados sobre demografia e território dos municípios brasileiros.

Kleba, M. E., \& Wendausen, A. (2009). Empoderamento: processo de fortalecimento dos sujeitos nos espaços de participação social e democratização política. Saúde e sociedade, 18, 733-743.

Leite, K. D. C., Maia, M. L. A., \& dos Santos, E. M. (2019). Planos de mobilidade urbana: avaliação qualitativa da participação popular em conformidade com a lei de mobilidade urbana: o caso do município de Olinda-PE.

Lilien, G. L., Rangaswamy, A., \& Van den Bulte, C. (2000). Diffusion models: Managerial applications and software. New-product diffusion models, 11.

de Luca, S. (2014). Public engagement in strategic transportation planning: An analytic hierarchy process based approach. Transport Policy, 33, 110-124. https://www.sciencedirect.com/science/article/pii/S0967070X14000687

Maia, A. A. (2015). Importância da audiência pública como mecanismo de participação social em projetos de transportes. Universidade de Brasília.

Portella, A. A., Pacheco, R. M. R., \& Flexor, M. H. O. (2020). Participação popular no processo de elaboração do orçamento participativo. A experiência de Porto Alegre. REVISTA QUAESTIO IURIS, 13(03), 1540-1571.

Quick; Kathryn S., \& Zhao, Z. (2011). Suggested Design and Management InTechniques for Enhancing Public Engagement in\nTransportation Policymaking, 52. http://www.cts.umn.edu/Publications/ResearchReports/reportdetail.html?id=2066

Ratcliff, R., \& Doshi, K. (2016). Using the Bass Model to Analyze the Diffusion of Innovations at the Base of the Pyramid. Business \& Society, 55(2), 271-298. https://doi.org/10.1177/0007650313479529

Rolnik, R., Pinheiro, O. M., \& others. (2004). Plano Diretor Participativo: guia para elaboração pelos municípios e cidadãos. Ministério das Cidades. 
Research, Society and Development, v. 11, n. 2, e2511225316, 2022

(CC BY 4.0) | ISSN 2525-3409 | DOI: http://dx.doi.org/10.33448/rsd-v11i2.25316

Rowe, G., \& Frewer, L. J. (2000). Public Participation Methods: A Framework for Evaluation. Science, Technology, \& Human Values, 25(1), 3-29. https://doi.org/10.1177/016224390002500101

Sewell, Wrderrick Phillips, S. U. S. A. N. D. (1979). Models for the evaluation of public participation programmes. Natural Resources Journal, 19(2), 337-358. http://www.jstor.org/stable/24881695

de Sousa Santos, B. V. (1998). Participatory Budgeting in Porto Alegre: Toward a Redistributive Democracy. Politics \& Society, 26(4), 461-510. https://doi.org/10.1177/0032329298026004003

Spencer, C. S. (1998). A Mathematical Model of Primary State Formation. Cultural Dynamics, 10(1), 5-20. https://doi.org/10.1177/092137409801000101

Spencer, C. S. (2014). Modeling the evolution of bureaucracy: Political-economic reach and administrative complexity. Social Evolution and History, 13(1), $42-66$.

Tomazette, M. (2008). A contribuição metodológica de Max Weber para a pesquisa em ciências sociais. Universitas Jus, 1.

Wagner, J. (2013). Measuring Performance of Public Engagement in Transportation Planning: Three Best Principles. Transportation Research Record, 2397(1), 38-44. https://doi.org/10.3141/2397-05

Wahl, C. (2013). Swedish municipalities and public participation in the traffic planning process - Where do we stand? Transportation Research Part A: Policy and Practice, 50, 105-112. https://www.sciencedirect.com/science/article/pii/S0965856413000190 